Marc BERGÈRE et Jean LE BIHAN [dir.], Fonctionnaires dans la tourmente. Épurations administratives et transitions politiques à l'époque contemporaine, Chêne-Bourg, Georg, 2009, 301 p. ISBN : 978-2-8257-0976-4. 22 euros.

\title{
Christophe Voilliot
}

\section{(2) OpenEdition \\ Journals}

Édition électronique

URL : http://journals.openedition.org/rh19/4014

DOI : 10.4000/rh19.4014

ISSN : $1777-5329$

Éditeur

La Société de 1848

Édition imprimée

Date de publication : 15 juillet 2010

Pagination : 162-163

ISSN : 1265-1354

Référence électronique

Christophe Voilliot, « Marc BERGÈRE et Jean LE BIHAN [dir.], Fonctionnaires dans la tourmente. Épurations administratives et transitions politiques à l'époque contemporaine, Chêne-Bourg, Georg, 2009, 301 p. ISBN : 978-2-8257-0976-4. 22 euros. », Revue d'histoire du XIXe siècle [En ligne], 40 | 2010, mis en ligne le 18 décembre 2010, consulté le 22 septembre 2020. URL : http:// journals.openedition.org/rh19/4014; DOI : https://doi.org/10.4000/rh19.4014

Ce document a été généré automatiquement le 22 septembre 2020

Tous droits réservés 


\title{
Marc BERGÈRE et Jean LE BIHAN [dir.], Fonctionnaires dans la tourmente. Épurations administratives et transitions politiques à l'époque contemporaine, Chêne-Bourg, Georg, 2009, 301 p. ISBN : 978-2-8257-0976-4. 22 euros.
}

\author{
Christophe Voilliot
}

Le temps passé depuis la parution du dernier livre de synthèse sur ce sujet ${ }^{1}$ confère à ce volume une réelle pertinence. Comme le soulignent dans l'introduction les coordinateurs de l'ouvrage, Marc Bergère et Jean Le Bihan, de nouvelles perspectives de recherche sont apparues à l'aune des épurations les plus récentes ${ }^{2}$ et des travaux portant sur les fonctionnaires "intermédiaires $»^{3}$ ou territoriaux. Sans vouloir bouleverser une chronologie bien établie des épurations, ils se proposent de restituer "l'épaisseur sociale du phénomène" (p.10) dans le cadre d'une histoire des représentations qui ne soit pas le prolongement d'une lecture politique des pratiques inscrites dans les changements de régimes. Il s'agit, par conséquent, « de réfléchir à la façon dont le lien entre l'État et ses agents se décompose en période d'exception politique » (p. 11).

2 Serge Bianchi présente une scansion des épurations de la période révolutionnaire articulée autour de quatre ruptures (la Constituante, la Convention, le Directoire, le 18 Brumaire) qui sont autant de tentatives pour inscrire dans un ordre institutionnel les compétences et les hiérarchies administratives. Plutôt que de regarder les 
fonctionnaires de cette époque comme des «girouettes", il insiste sur les recompositions successives et la véritable autonomie dont disposent les institutions locales jusqu'à l'an II. Ce texte, qui est aussi un bilan historiographique fort utile, se conclut par un appel à inventorier et à étudier de nouvelles configurations administratives et politiques. Pierre Karila-Cohen nous propose un portrait de Bourgeois de Jessaint, préfet «inépurable» de la Marne de 1800 à 1838, en s'interrogeant sur les causes d'une telle longévité administrative. Les soutiens dont il bénéficie dans la capitale et sa popularité locale n'y sont pas pour rien, mais sa carrière repose aussi sur un «art de ne se pas se compromettre » (p. 85) consommé. Fort des travaux récents sur l'histoire de la gendarmerie, Arnaud-Dominique Houte inscrit le cycle d'épurations dans les transformations institutionnelles et la professionnalisation de ce corps. Le siècle passant, les gendarmes apprennent à mettre en avant l'excuse de l'obéissance passive pour échapper à des sanctions parmi lesquelles les mutations l'emportent sur les révocations à partir de la Troisième République. Il n'en va pas de même de la magistrature étudiée par Alain Bancaud. L'exclusion de ceux qui se sont compromis avec le régime précédent est la conséquence d'une « exigence d'alignement politique" (p.151) réaffirmée tout au long du siècle, particulièrement pour les membres du Conseil d'État et les juges du siège dont l'inamovibilité ne vaut que pour les périodes de stabilité politique et institutionnelle. Les conséquences individuelles en sont néanmoins limitées par la pratique du chassé-croisé consistant à réintégrer à chaque nouvelle épuration les victimes de la précédente. L'intéressante étude d'Emmanuel Bellanger sur les fonctionnaires municipaux a le mérite de nuancer la thèse de leur instrumentalisation politique et partisane ${ }^{4}$. Selon lui, « dans le système du gouvernement des villes, les vagues d'épuration érigées en mode d'administration n'ont pas eu la rigueur et la systématisation qu'on leur a prêtées » (p. 181). Il en apporte la preuve à partir de l'étude des carrières des fonctionnaires issus de l'École nationale d'administration municipale créée en 1922 dans le département de la Seine. Deux contributions consacrées à l'épuration des fonctionnaires allemands en 1919 et entre 1945 et 1949 (Marie-Bénédicte Vincent) et à celle des préfets de la République sociale italienne (Valeria Galimi) complètent ce volume.

Le recours à la notion de transition politique apporte-t-elle une plus-value à l'étude des pratiques d'épuration? Restant prudemment à distance des débats théoriques qui ont surgi en science politique à mesure de l'inflation des travaux portant sur les «transitions démocratiques" contemporaines ${ }^{5}$, les différents contributeurs de cet ouvrage n'apportent guère la preuve de son caractère heuristique. En cela, les travaux portant sur les personnels d'administration restent tributaires d'une histoire des représentations des cadres institutionnels dans lesquels ils se meuvent, non sans risque parfois.

\section{NOTES}

1. . Paul Gerbot [dir.], Les épurations administratives, XIX et XXe siècles, Genève, Droz, 1977. 
2. . Marc Olivier Baruch [dir.], Une poignée de misérables. L'épuration de la société française après la Seconde Guerre mondiale, Paris, Fayard, 2003.

3. Jean Le Bihan, Au service de l'État. Les fonctionnaires intermédiaires au XIX siècle, Rennes, Presses universitaires de Rennes, 2008.

4. . Jean-Yves Nevers, « Du clientélisme à la technocratie : cent ans de démocratie communale dans une grande ville, Toulouse ", Revue française de science politique, XXXIII, 3, 1983, p. 426-454.

5. . Michel Dobry, «Les voies incertaines de la transitologie: choix stratégiques, séquences historiques, bifurcations et processus de "path dependence"», Revue française de science politique, L, n 4-5, 2000, p. 579-614. 